\title{
Biological role of interleukin 1 receptor antagonist isoforms
}

\author{
William P Arend, Carla J Guthridge
}

\begin{abstract}
The interleukin 1 receptor antagonist (IL1Ra) family of molecules now includes one secreted isoform (sIL1Ra) and three intracellular isoforms (icIL1Ra1, 2, and 3). Extensive evidence indicates that the sole biological function of SIL1Ra seems to be to competitively inhibit IL1 binding to cell-surface receptors. Although intracellular IL1Ra1 may be released from keratinocytes under some conditions, the intracellular isoforms of IL1Ra may carry out additional as yet poorly defined roles inside cells. Maintenance of a balance between IL1 and IL1Ra is important in preventing the development or progression of inflammatory disease in certain organs. Both the secreted and intracellular isoforms of IL1Ra contribute to maintenance of this balance. An allelic polymorphism in intron 2 of the IL1Ra gene $(I L 1 R N \star 2)$ predisposes to the development or severity of a variety of human diseases largely of epithelial cell origin. Both the impaired production of IL1Ra and the overproduction of IL1 $\beta$ are related to the presence of this allele. Restoration of the balance between IL1Ra and IL1 through a variety of approaches is a therapeutic goal in specific chronic inflammatory diseases.

(Ann Rheum Dis 2000;59(suppl I):i60-i64)
\end{abstract}

The interleukin 1 receptor antagonist was originally described as a secreted molecule (sIL1Ra) from monocytes and macrophages. The primary function of sIL1Ra seems to be to competitively inhibit the binding of IL1 to cell surface receptors. Three intracellular isoforms of this molecule have now been described. The biological role of the intracellular isoforms of IL1Ra remains unclear. Although these molecules may be released from cells to function as receptor antagonists, the intracellular isoforms of IL1 Ra may carry out additional roles inside cells. This review will summarise characteristics of the described IL1 Ra isoforms, the role of these molecules in biology, and reported disease associations of allelic polymorphisms of the IL1Ra gene.

Division of

Rheumatology,

University of Colorado

Health Sciences

Center, Denver, 4200

East Ninth Avenue,

Denver, CO 80262,

USA

Correspondence to:

Dr Arend

(William.Arend@UCHSC.edu) sylated species of 22-25 kDa from monocytes, macrophages, neutrophils, hepatocytes, microglial cells, and other cells. sIL1Ra binds to types I and II IL1 receptors (IL1RI and IL1RII) on plasma membranes of a variety of cells with an avidity near equal to the two agonists, IL $1 \alpha$ and IL $1 \beta$, yet fails to induce receptor internalisation or discernible intracellular responses. Target cells exhibit full biological responses to occupancy of only three to five receptors per cell by IL1 agonists, and most cells express a relatively large number of the biologically active IL1RI. Because of this extreme sensitivity to IL1 stimulation and a large number of free receptors per cell, 100-fold excess or greater amounts of IL1Ra must be present to effectively inhibit cell stimulation. ${ }^{3}$

The extended IL1Ra gene (IL1RN) is present on the long arm of human chromosome 2 at band $2 \mathrm{q} 14$, adjacent to the genes for IL $1 \alpha$ and IL1 $\beta .^{4-6}$ The first described intracellular isoform of IL1 Ra (icIL1Ra1) is created by an alternative transcriptional splice of an upstream exon into the amino terminus of sIL1Ra, creating a $18 \mathrm{kDa}$ protein that lacks a signal peptide. ${ }^{7}$ icIL1 Ra1 is a major protein in keratinocytes and other epithelial cells, and is also produced with delayed kinetics by monocytes and macrophages. A cDNA for a second intracellular isoform of IL1Ra (icIL1Ra2) was cloned from human neutrophils, and contained a $63 \mathrm{bp}$ sequence inserted between the first and second exons for icIL1Ra $1 .{ }^{89}$ This cDNA was present in fibroblasts, keratinocytes, and human myelomonocytic cells, although the predicted $25 \mathrm{kDa}$ protein has not yet been described as a natural product in any cell. Thus, it remains unknown whether icIL1Ra2 exists as a protein in vivo. A third intracellular isoform of IL1Ra (icIL1Ra3) was recently described as a $16 \mathrm{kDa}$ product of predominately the sIL1Ra mRNA, created by alternative translational initiation. ${ }^{10}{ }^{11}$ icIL1Ra3 is a major protein in hepatocytes and neutrophils, and also is present in smaller amounts in monocytes, macrophages, and keratinocytes.

The binding characteristics of each isoform of IL1Ra have been examined with IL1R in both solid phase and soluble forms. Recombinant icIL1Ra1 and sIL1Ra exhibited equivalent binding to immobilised IL1RI, whereas icIL1Ra3 bound fourfold to fivefold less avidly. $^{10}$ The biological activities of these isoforms of IL1 Ra exhibited similar characteristics in the murine thymocyte assay, with sIL1Ra and icIL1 Ra1 showing equivalent inhibition of IL1 stimulation and icILRa3 being fourfold less active. Recombinant icIL1Ra1 and icIL1Ra2 exhibited similar patterns of 
inhibition of IL1 induced expression of E-selectin on endothelial cells. ${ }^{8}$ Binding studies with soluble IL1R (sIL1R) indicated that IL1 $\beta$ bound more avidly to sIL1RII than IL $1 \alpha$ or sIL1Ra, primarily because of a slow dissociation rate, whereas sIL1Ra bound more avidly to sIL1RI in comparison to IL $1 \alpha$ and IL $1 \beta .{ }^{12}$ The binding of intracellular isoforms of IL1 Ra to sIL1R have not been examined.

In summary, one secreted and possibly three intracellular isoforms of IL1Ra have been described. All of these IL1Ra isoforms are capable of inhibiting the stimulatory effects of IL1 on cells, although icIL1Ra3 weakly blocks IL1. Why has nature provided this variety of IL1 Ra isoforms and what is the biological relevance of this molecular heterogeneity?

\section{Role of sIL1Ra in biology}

The results of a variety of studies over the past 10 years indicate that the major function of sIL1Ra is to regulate the pleiotropic effects of IL1 by competitively blocking its binding to cell surface receptors. ${ }^{13}$ Thus, sIL1Ra functions as a major naturally occurring antiinflammatory protein; when the balance between IL1 and IL1Ra is upset, inflammatory disease and tissue damage may ensue. Evidence supporting this conclusion can be derived from studies on the production of endogenous IL1Ra, and on the effects of administration of recombinant IL1 Ra in animal models of disease. Further support for an important role for sIL1Ra in biology can be obtained from recent studies on IL1Ra transgenic and knockout mice. Lastly, observations in human diseases indicate the importance of adequate production of sIL1Ra to prevent or modify injurious IL1 effects.

The administration of neutralising antibodies to IL1Ra led to an earlier onset and more severe course in numerous animal models of disease. These animal models include: lipopolysaccharide induced arthritis in rabbits, ${ }^{14}$ immune complex induced lung injury in rats, ${ }^{15}$ colitis in rabbits induced by formalin and

Table 1 Animal models of disease treated with recombinant IL1Ra

Collagen induced arthritis in mice

Streptococcal cell wall induced arthritis in rats

Immune complex induced arthritis in mice

Antigen induced arthritis in rabbits

Osteoarthritis in dogs

Septic shock in rabbits, baboons, rats and mice

Bacterial meningitis in rabbits

Ischaemic brain injury in rats

Experimental allergic encephalomyelitis in rats

Streptococcal cell wall induced colitis in rats

Experimental shigellosis in rabbits

Immune complex induced colitis in rabbit

Acetic acid induced colitis in rats

Lipopolysaccharide induced pleurisy in rabbits

Monocrotaline induced pulmonary hypertension in rats

Allergen induced late asthmatic reaction in guinea pigs

Bleomycin or silica induced pulmonary fibrosis in mice

Immune complex induced lung injury in rats

Ischaemia/reperfusion lung injury in rats

Crescentic glomerulonephritis in rats

Anti-glomerular basement membrane antibody induced glomerulonephritis in rats

Pre-term delivery in mice induced by IL1

Osteoclast formation and bone resorption in ovariectomised mice and rats

Hepatic fibrosis induced by dimethylnitrosamine in rats

Post-cardiac transplant coronary arteriopathy in piglets

Graft versus host disease in mice

Streptozotocin induced diabetes in mice

Reproduced by permission from Arend et al. ${ }^{13}$ immune complexes, ${ }^{16}$ bacteria induced hepatitis in mice, ${ }^{17}$ and granuloma formation in mice. ${ }^{1819}$ These observations indicate that the endogenous production of IL1 Ra is important in limiting inflammation and tissue damage in animal models of disease characterised by an excess production of IL1.

The administration of recombinant human sIL1Ra has been effective in preventing the onset of disease, or in ameliorating established disease, in numerous animal models, as summarised in table 1 and in a recent review. ${ }^{13}$ However, large amounts of sIL1Ra delivered by constant infusion or daily injections were required in these studies, for reasons summarised above. Gene therapy approaches have also been successful in treating animal models of disease with IL1Ra, primarily models of rheumatoid arthritis or osteoarthritis. ${ }^{13}$ These studies have used both ex vivo approaches, with introduction of the IL1 Ra cDNA into cultured synovial fibroblasts using retroviral vectors, or in vivo gene therapy using intra-articular injection of adenoviral vectors. Gene transfer of IL1Ra into neuronal cells, osteoblasts, or haematopoietic stem cells also has been described, opening the possibility of IL1Ra gene therapy for diseases of the CNS, bone, or bone marrow.

The results of studies in mice made transgenic for the overexpression of sIL1Ra, or rendered genetically deficient in the production of all isoforms of IL1Ra, further support the importance of maintaining a balance between IL1Ra and IL1 in the prevention of disease. IL1 Ra knockout mice were smaller, more susceptible to lethal endotoxaemia, and less susceptible to listeria infection, in comparison with normal littermates, whereas sIL1 Ra transgenic mice exhibited the opposite phenotype. ${ }^{20}$ These observations indicate that the presence of adequate amounts of IL1 Ra are important in limiting the deleterious effects of endotoxin, while IL1 is important in host resistance to Listeria (and to other intracellular pathogens). Similar results were obtained in collagen induced arthritis in mice where overexpression of sIL1Ra led to a reduction in the incidence and severity of disease whereas the absence of all isoforms of IL1Ra produced the opposite phenotype. ${ }^{21}$ Recent studies in mice genetically deficient in IL $1 \alpha$, IL $1 \beta$, or IL1 Ra, indicated the importance of IL1Ra both in normal physiology as well as in regulation of fever and neuroendocrine responses to stress. ${ }^{22}$

Lastly, maintenance of an adequate balance between IL1Ra and IL1 may have an important role in the prevention of inflammatory disease of the joints or arteries in the presence of other genes predisposing to disease. IL1Ra deficient mice backcrossed into the $\mathrm{BALB} / \mathrm{cA}$ background, but not mice on a C57BL/6 background, spontaneously developed an inflammatory arthritis resembling rheumatoid arthritis in humans. ${ }^{23}$ Furthermore, IL1 Ra knockout mice bred on a MFI $\times 129$ background spontaneously developed an inflammatory arterial disease similar to polyarteritis nodosa in humans. ${ }^{24}$ The other genes predisposing to tissue damage in these animal models of disease 
have not been established, but conceivably they could lead to increased IL1 production. However, these important observations indicate that adequate levels of IL1 Ra are necessary to counter the potentially injurious effects of IL1 in tissues where other mechanisms may possibly stimulate the local production of IL1.

The circulating levels of IL1Ra in human diseases, and the local production of this antiinflammatory cytokine in various tissues, have been examined in some detail. ${ }^{13}$ sIL-1Ra is produced by hepatocytes as an acute phase protein and increased levels have been described in the circulation of patients with a wide variety of inflammatory, infectious, and neoplastic diseases, as well as following surgery. ${ }^{25}$ However, studies in many human diseases indicate that the level of production of all isoforms of IL1Ra in local tissues may not be sufficient to effectively block the inflammatory consequences of local IL1 production. These observations suggest that mechanisms regulating IL1Ra production by macrophages and other cells in diseased tissues may be inadequate. Whether sIL1Ra in the circulation, produced as an acute phase protein, diffuses into tissues and inhibits IL1 effects is not known.

\section{Role of icIL1Ra in biology}

The biological effects of the intracellular isoforms of IL1Ra have been less thoroughly investigated. As summarised above, icIL1Ra1 and icIL1Ra2 bind equally as well as sIL1Ra to IL1RI and inhibit the stimulatory effects of IL1. In contrast, icIL1Ra3, which predominates in neutrophils and hepatocytes, is a weak inhibitor of receptor binding of IL $1 .{ }^{10}$ Although the intracellular isoforms of IL1Ra are synthesised in the cytoplasm and appear not to be transported to the nucleus, keratinocytes may release icIL1Ra1 under some conditions. In addition to secretion of icIL1Ral by an unknown leaderless pathway, keratinocytes may express icIL1Ra1 on their plasma membrane with release from that location as well. ${ }^{26}$ Although keratinocytes possess small amounts of the active IL1RI, the biologically inactive IL1RII predominates on these cells, particularly after activation. ${ }^{27}$ IL1RII are cleaved from expressing cells, avidly bind IL $1 \beta$, and function in the cell microenvironment as IL1 inhibitors. Thus, although keratinocytes are capable of releasing small amounts of icIL1Ra1, the functional importance of this cytokine as an extracellular receptor blocker in the skin has not been established.

Intracellular IL1Ra1 also may block IL1 induced gene expression inside cells without release to the exterior. Human ovarian and cervical cancer cells expressing icIL1Ralexhibited a decrease in IL1 stimulated GRO and IL8 mRNA expression in comparison with cell lines lacking icIL1Ra $1{ }^{28}$ Furthermore, expression of icIL1Ral in nonproducing cells, using a retroviral expression vector, led to a pattern of response analogous to that seen with cells spontaneously producing icIL1Ra1. This effect of icIL1Ra1 was not mediated at the level of transcription but appeared to involve alterations in GRO $\mathrm{mRNA}$ stability or degradation. In other studies, fibroblasts from patients with systemic sclerosis expressed higher levels of icIL1Ra1 in vitro than did fibroblasts from normal controls, after stimulation with IL $1 \beta$ or $\mathrm{TNF} \alpha .^{29}$ Additional studies indicated that intracellular proIL $1 \alpha$, and not mature IL $1 \alpha$ released into the cell microenvironment, induced the production of icIL1Ra1 by the fibroblasts. Whether the high levels of production of icIL1Ra1 by scleroderma fibroblasts were related to the abnormal functional characteristics of these cells was not determined.

The role of icIL1Ra1 in rhinovirus (RV) upper respiratory infections in humans was examined in recent studies. icIL1Ra1 protein was readily detected in the nasal washings of normal volunteers, with the levels markedly increasing after symptomatic RV infection. ${ }^{30}$ Moreover, the icIL1Ra1 production in vivo was prolonged and accompanied the clinical resolution of symptoms. Unstimulated normal respiratory epithelial cells contained icIL1Ra1 mRNA and protein, with release of the protein after RV infection in the absence of increased mRNA levels. These observations suggest that icIL1Ra1 may play an important part in the resolution of RV infections. This cytokine may be present constitutively in respiratory epithelial cells, as is true of keratinocytes, with release by unknown translational or post-translational mechanisms. However, these studies did not investigate any possible function of icIL1Ra 1 inside epithelial cells.

In summary, the biological role of icIL1Ra1 remains unclear. Keratinocytes, or other epithelial cells, may apparently release this cytoplasmic protein under certain conditions, and it may function as a receptor blocker in the cell microenvironment. Some evidence suggests that this and other intracellular isoforms of IL1Ra may carry out additional functions inside cells. We are investigating this possibility using a number of experimental approaches.

\section{Allelic polymorphisms of the IL1Ra gene and disease}

Further evidence for the biological importance of a balance between IL1 and IL1Ra can be derived from recent studies on an allelic polymorphism of the IL1Ra gene. A polymorphism exists in intron 2 of IL1RN caused by two to six copies of an 86 bp tandem repeat. ${ }^{31}$ The A1 allele, containing four repeats, is the most common allele and is found in $73.6 \%$ of the population. Allele A2 (IL1RN ${ }^{\star} 2$ ) contains two repeats, is found in $21.4 \%$ of the population, and has been associated with a variety of human diseases, primarily of epithelial cells or tissues. An association of allele A2 with an increased prevalence of ulcerative colitis (UC), but not with Crohn's disease, has been described in some but not all population groups (summarised by Tountas et $a \beta^{32}$.) This association may not exist in Northern European ethnic groups, but it has been found in both in American-based Hispanic and Jewish populations. $^{32}$ Other disease associations of $\mathrm{IL}_{1 \mathrm{RN}^{\star}} 2$ include alopecia areata, $^{33}$ lichen 
sclerosus, ${ }^{34}$ psoriasis, ${ }^{35}$ multiple sclerosis, ${ }^{36}$ diabetic nephropathy, ${ }^{37}$ hypochlorhydria and gastric cancer, ${ }^{38}$ and susceptibility to severe sepsis. $^{39}$

A possible association with allele IL $1 \mathrm{RN}^{\star} 2$ has also been studied in some rheumatic diseases. Systemic lupus erythematosus, particularly photosensitivity and discoid skin lesions, was observed to be increased in both white $^{4041}$ and Japanese ${ }^{42}$ populations carrying IL1RN*2. However, this allele may influence the severity of SLE rather than susceptibiity. ${ }^{40}$ IL $1 R N^{\star} 2$ is also associated with more severe forms of Sjögren's syndrome, with the levels of IL1Ra protein being decreased in saliva but increased in serum. ${ }^{43}$ Lastly, the IL1 Ra intron 2 polymorphism did not influence the susceptibility to or severity of rheumatoid arthritis. ${ }^{44}$

The possible mechanisms of IL1RN ${ }^{\star} 2$ association with disease remain unclear. Steady state levels of IL1Ra mRNA in human keratinocytes, presumably representing icIL1Ral mRNA, were not related to the IL1RN allelic polymorphism. ${ }^{45}$ In early studies increased IL1 Ra secretion, but not cell associated IL1Ra, as well as reduced IL $1 \alpha$ production were observed in cytokine stimulated monocytes from IL $1 \mathrm{RN}^{\star} 2$ normal donors. ${ }^{46}$ However, these results have not been substantiated in more recent studies where total IL1 Ra production (both cell associated and secreted) was decreased in unstimulated monocytes or stimulated cells from both normal donors or UC patients carrying the IL1RN`2 allele. ${ }^{32}$ The possibility also exists that a gene linked to or associated with IL1RN* 2 might explain the apparent disease association. Indeed, the presence of IL1RN`2 is associated with increased monocyte production of IL1 $\beta$, apparently through strong linkage disequilibrium with the IL1 $\beta-31 \mathrm{~T}$ diallelic polymorphism. ${ }^{38} 47$ Thus, more severe disease in people carrying allele 2 of the IL1Ra gene may be related to an imbalance between IL1Ra and IL1 $\beta$, with both increased production of IL1 $\beta$ and possibly decreased IL1Ra.

\section{Summary}

IL1Ra production in many cells and tissues immediately follows after that of IL1. Mature IL1 may actually stimulate production of sIL1Ra, and proIL1 $\alpha$ inside fibroblasts may induce production of icIL1Ra1. The sole function of sIL1Ra in the cell microenvironment is to competitively inhibit receptor binding of IL1. Thus, the biological role of sIL1 Ra may be to dampen or attenuate the potent biological consequences of IL1 both in normal physiology and in pathophysiological conditions. icIL1Ra 1 may also inhibit receptor binding of IL1 after release from epithelial cells, but the intracellular structural variants of IL1Ra may carry out additional roles inside cells not involving interaction with IL1 receptors. ProIL $1 \alpha$ is synthesised in the cytoplasm followed by movement to the plasma membrane, or to the nucleus where the pro-piece may increase transcription. Whether icIL1Ra1 influences these intracellular effects of proIL $1 \alpha$ has not been examined. However, the balance between IL1 Ra and IL1 in some tissues, such as the joint and the vessel wall, may influence the relative propensity for the development of inflammatory disease. Whether this balance pertains only to sIL1Ra, or also includes intracellular isoforms of IL1 Ra, may depend on the particular cell or tissue involved. The association of various inflammatory diseases, largely of epithelial tissues, with allele IL $1 \mathrm{RN}^{\star} 2$ may be related to both decreased production of IL1Ra and to increased production of ILl $\beta$. Rather than the exogenous administration of recombinant sIL1Ra, or delivery of IL1Ra by gene therapy, stimulation or enhancement of endogenous IL1Ra production may be a more physiological approach to treatment of human disease.

1 Arend WP. Interleukin 1 receptor antagonist. A new member of the interleukin 1 family. J Clin Invest member of the

2 Arend WP. Interleukin-1 receptor antagonist. Adv Immunol 1993;54:167-227

3 Arend WP, Welgus HG, Thompson RC, Eisenberg SP. Biological properties of recombinant monocyte-derived interleukin 1 receptor antagonist. J Clin Invest 1990;85:1694-7.

4 Steinkasserer A, Spurr NK, Cox S, Jeggo P, Sim RB. The human IL-1 receptor antagonist gene (IL1RN) maps to chromosome $2 \mathrm{q} 14-\mathrm{q} 21$, in the region of the IL-1 $\alpha$ and IL-1 $\beta$ loci. Genomics 1992;13:654-7.

5 Patterson D, Jones C, Hart I, Bleskan J, Berger R, Geyer D, et al. The human interleukin-1 receptor antagonist IL1RN) gene is located in the chromosome $2 \mathrm{q} 14$ region. Genomics 1993;15:173-6.

6 Nicklin MJH, Weith A, Duff GW. A physical map of the region encompassing the human interleukin-1 $\alpha$, interleukin-1 $\beta$, and interleukin-1 receptor antagonist genes. Genomics 1994;19:382-4.

7 Haskill S, Martin G, Van Le L, Morris J, Peace A, Bigler CF, t al. cDNA cloning of an intracellular form of the human et al. cDNA cloning of an intracellular form of the human
interleukin 1 receptor antagonist associated with epitheinterleukin 1 receptor antagonist associated
lium. Proc Natl Acad Sci 1991;88:3681-5.

8 Muzio M, Polentarutti N, Sironi M, Poli G, de Gioia L, Introna $\mathrm{M}$, et al. Cloning and characterization of a new isoform of the interleukin 1 receptor antagonist. J Exp Med 1995; 182:623-8.

9 Muzio M, Polentarutti N, Facchetti F, Giuseppe P, Doni A, Sironi M, et al. Characterization of type II intracellular IL-1 receptor antagonist [IL-1ra3]: a depot IL-1 ra. Eur J Immunol 1999;29:781-8.

10 Malyak M, Guthridge JM, Hance KR, Dower SK, Freed JH, Arend WP. Characterization of a low molecular weight isoform of IL-1 receptor antagonist. J Immunol 1998;161: 1997-2003.

11 Malyak M, Smith MF, Abel AA, Hance KR, Arend WP. The differential production of three forms of IL-1 receptor differential production of three forms of IL-1 receptor
antagonist by human neutrophils and monocytes. J Immuantagonist by human neut

12 Arend WP, Malyak M, Smith MF, Whisenand TD, Slack JL, Sims JE, et al. Binding of IL- $1 \alpha$, IL-1 $\beta$, and IL- 1 receptor antagonist by soluble IL-1 receptors and levels of soluble IL-1 receptors in synovial fluids. J Immunol 1994;153: 4766-74.

13 Arend WP, Malyak M, Guthridge CJ, Gabay C. Interleukin-1 receptor antagonist: role in biology. Annu Rev Immunol 1998;16:27-55.

14 Fukumoto T, Matsukawa A, Ohkawara S, Takagi K, Yoshinaga $M$. Administration of neutralizing antibody against rabbit IL-1 receptor antagonist exacerbates lipopolysaccharide-induced arthritis in rabbits. Inflamm Res 1996;45:479-85.

15 Shanley TP, Peters JL, Jones ML, Chensue SW, Kunkel SL, Ward PA. Regulatory effects of endogenous interleukin-1 receptor antagonist protein in immunoglobulin $\mathrm{G}$ immune complex-induced lung injury. J Clin Invest 1996;97:96370 .

16 Ferretti M, Casini-Raggi V, Pizarro TT, Eisenberg SP, Nast CC, Cominelli F. Neutralization of endogenous IL-1 receptor antagonist exacerbates and prolongs inflammation in rabbit immune colitis. J Clin Invest 1994;94:449-453.

17 Fujioka N, Mukaida N, Harada A, Akiyama M, Kasahara T, Kuno K, et al. Preparation of specific antibodies against murine IL-1ra and the establishment of IL-1ra as an endogenous regulator of bacteria-induced fulminant hepatitis in mice. J Leukoc Biol 1995;58:90-9.

18 Chensue SW, Bienkowski M, Eessalu TE, Warmington KS, Hershey SD, Lukacs NW, et al. Endogenous IL-1 receptor antagonist protein (IRAP) regulates schistosome egg ntagon protein (IRAP) egg J Immunol 1993;151:3654-62.

19 Ruth JH, Bienkowski M, Warmington KS, Lincoln PM, Kunkel SL, Chensue SW. IL-1 receptor antagonist [IL-1 ra] expression, function, and cytokine-mediated regulation during mycobacterial and schistosomal antigen-elicited granuloma formation. J Immunol 1996;156:2503-9. 
20 Hirsch E, Irikura VM, Paul SM, Hirsh D. Functions of interleukin 1 receptor antagonist in gene knockout and overproducin

21 Ma Y, Thornton S, Boivin GP, Hirsh D, Hirsch R, Hirsch E. Altered susceptibility to collagen-induced arthritis in transgenic mice with aberrant expression of interleukin-1 receptor antagonist. Arthritis Rheum 1998;48:1798-805.

22 Horai R, Asano M, Sudo K, Kanuka H, Suzuki, Nishihara $\mathrm{M}$, et al. Production of mice deficient in genes for interleukin (IL)-1 $\alpha$ IL-1 $\beta$, IL- $1 \alpha / \beta$, and IL-1 receptor antagonist shows that IL-1 $\beta$ is crucial in turpentineinduced fever development and glucocorticoid secretion. Exp Med 1998;187:1463-75.

23 Horai R, Saijo S, Tanioka H, Nakae S, Sudo K, Okahara A, et al. Development of chronic inflammatory arthropathy resembling rheumatoid arthritis in interleukin 1 receptor resembling reumatoid arthritis in interleukin 1 receptor

24 Nicklin MJH, Hughes DE, Barton JL, Ure JM, Duff GW. Arterial inflammation in mice lacking the interleukin 1 Arterial inflammation in mice lacking the interleukin

25 Gabay C, Smith MF, Eidlen D, Arend WP. Interleukin receptor antagonist (IL-1Ra) is an acute-phase protein. J Clin Invest 1997:99:2930-40

26 Corradi A, Franzi AT, Rubartelli A. Synthesis and secretion of interleukin- $1 \alpha$ and interleukin-1 receptor antagonist during differentiation of cultured kerantinocytes. Exp Cell Res 1995;217:355-62

27 Groves RW, Giri J, Sims J, Dower SK, Kupper TS. Inducible expression of type 2 IL-1 receptors by cultured human keratinocytes. Implications for IL-1-mediated processes in epidermis. J Immunol 1995;154:4065-72.

28 Watson JM, Lofquist AK, Rinehart CA, Olsen JC, Makarov SS, Kaufman DG et al. The intracellular IL-1 receptor antagonist alters IL-1-inducible gene expression without blocking exogenous signaling by IL-1 $\beta$. J Immunol 1995; 155:4467-75.

29 Higgins GC, Wu Y, Postlethwaite AE. Intracellular IL-1 receptor antagonist is elevated in human dermal fibroblasts receptor antagonist is elevated in human dermal fibroblasts 1999; 163:3969-75.

30 Yoon HJ, Zhu Z, Gwaltney JM, Elias JA. Rhinovirus regulation of IL-1 receptor antagonist in vivo and in vitro: a potential mechanism of symptom resolution. J Immuno 1999; 162:7461-9.

31 Tarlow JK, Blakemore AIF, Lennard A, Solari R, Hughes $\mathrm{HN}$, Steinkasserer A, et al. Polymorphism in human IL-1 receptor antagonist gene intron 2 is caused by variable numbers of an 86-bp tandem repeat. Hum Genet 1993;91: 403-4.

32 Tountas NA, Casini-Raggi V, Yang H, di Giovine FS, Vecchi $\mathrm{M}, \mathrm{Kam} \mathrm{L}$, et al. Functional and ethnic association of allele 2 of the interleukin-1 receptor antagonist gene in ulcerative colitis. Gastroenterology 1999;117:806-13.

33 Tarlow JK, Clay FE, Cork MJ, Blakemore AIF, McDonagh AJG, Mesenger AG, et al. Severity of alopecia areata is Associated with a polyr associated with a polymorphism in the interleukin-1 recep-

34 Clay $\mathrm{FE}$, Cork MJ, Tarlow JK, Blakemore AIF, Harrington $\mathrm{CI}$, Lewis $\mathrm{F}$, et al. Interleukin 1 receptor antagonist gene polymorphism association with lichen sclerosus. Hum Genet 1994;94:407-10.

35 Bellaney GJ, Tyan TJ. Association between interleukin-1 receptor antagonist (IL-1 ra) gene polymorphism and earl and late-onset psoriasis. [Letter]. Br J Dermatol 1997;136: $147-8$.

36 Sciacca FL, Ferri C, Vandenbroeck K, Veglia F, Gobbi C, Martinelli $\mathrm{F}$, et al. Relevance of interleukin 1 receptor antagonist intron 2 polymorphism in Italian MS patients. Neurology 1999;52:1896-8.

37 Blakemore AIF, Cox A, Gonzalez AM, Maskill JK, Hughes $\mathrm{ME}$, Wilson RM, et al. Interleukin-1 receptor antagonist allele (IL1RN ${ }^{\star} 2$ ) associated with nephropathy in diabetes mellitus. Hum Genet 1996;97:369-74.

38 El-Omar EM, Carrington M, Chow WH, McColl KEL, Bream JH, Young HA, et al. Interleukin-1 polymorphisms associated with increased risk of gastric cancer. Nature 2000;404:398-402.

39 Fang XM, Schröder S, Hoeft A, Stüber F. Comparison of two polymorphisms of the interleukin-1 gene family: interleukin-1 receptor antagonist polymorphism contributes to susceptibility to severe sepsis. Crit Care Med 1999; $27: 1330-4$.

40 Blakemore AIF, Tarlow JK, Cork MJ, Gordon C, Emery P, Duff GW. Interleukin-1 receptor antagonist gene polymorphism as a disease severity factor in systemic lupus erythematosus. Arthritis Rheum 1994;37:1380-5.

41 Tjernström F, Hellmer G, Nived O, Truedsson L, Sturfelt G. Synergetic effect between interleukin-1 rreceptor antagonist allele (IL1RN`2) and MHC class II (DR17,DQ2) in determining susceptibility to systemic lupus erythematosus. Lupus 1999;8:103-8.

42 Suzuki H, Matsui Y, Kashiwagi H. Interleukin-1 receptor antagonist gene polymorphism in Japanese patients with systemic lupus erythematosus. Arthritis Rheum 1997;40: 389-90.

43 Perrier S, Coussediere C, Dubost JJ, Albuisson E, Sauvezie B. IL-1 receptor antagonist (IL-1RA) gene polymorphism in Sjogren's syndrome and rheumatoid arthritis. Clin Immunol Immunopathol 1998;87:309-13.

44 Cantagrel A, Navaux F, Loubet-Lescoulié P, Nourhashemi F, Enault G, Abbal $M$, et al. Interleukin-1 $\beta$, interleukinreceptor antagonist, interleukin-4, and interleukin-10 gene polymorphisms. Relationship to occurrence and severity of rheumatoid arthritis. Arthritis Rheum 1999;42:1093-100.

45 Clay FE, Tarlow JK, Cork MJ, Cox A, Nicklin MJH, Duff GW. Novel interleukin-1 receptor antagonist exon poly-
morphisms and their use in allele-specific mRNA assessmorphisms and their use in allele-

46 Danis VA, Millington M, Hyland VJ, Grennan D. Cytokine production by normal human monocytes: inter-subject variation and relationship to an IL-1 receptor antagonist (IL-1Ra) gene polymorphism. Clin Exp Immunol 1995;99: 303-10.

47 Santtila S, Savinainen K, Hurme M. Presence of the IL-1RA allele 2 (IL $1 \mathrm{RN}^{\star} 2$ ) is associated with enhanced IL-1 $\beta$ production in vitro. Scand J Immunol 1998;47:195-8. 